\title{
Terminology and Standards
}

In this ethnography I use the word "radiation" as an umbrella term and as shorthand to speak about the effects of the Fukushima nuclear accident. This usage is in keeping with the way I heard the people I worked with employ the term when referring to the accident and its aftermath. Radiation in this case refers to ionizing radiation, of which there are several types, including alpha, beta, neutron, and gamma radiation. Not all forms of radiation are equally noxious; neutron and alpha radiation cause more harm than beta or gamma radiation. A characteristic of ionizing radiation is that when interacting with an atom, it has enough energy to remove an electron, thereby causing the atom to become charged. The World Health Organization (2016) states that "ionizing radiation is a type of energy released by atoms that travels in the form of electromagnetic waves (gamma or X-rays) or particles (neutrons, beta or alpha). The spontaneous disintegration of atoms is called radioactivity, and the excess energy emitted is a form of ionizing radiation.... Ionizing radiation has always been a part of the human environment. Along with natural radioactive sources present in the Earth's crust and cosmic radiation, man-made sources also contribute to our continuous exposure to ionizing radiation."

The Fukushima nuclear accident released a range of pollutants from the reactors into the surrounding areas. The releases consisted primarily of iodine-131, cesium-137, and cesium-134. In addition, researchers have detected smaller amounts of strontium-80 and plutonium (Yoshida and Kanda 2012). Radioactive materials are constantly decaying, and the rate at which they decay is expressed in the length of their half-life, which is when their radioactivity has decayed by half. Iodine-131 has a half-life of eight 
days; although it can be a noxious contaminant for human health, within a couple of months little danger will be left from the substance. In contrast to the short half-life of iodine, cesium takes longer to decay: cesium-134 has a half-life of two years, and cesium-137 has a half-life of thirty years.

Two units of measurement will often be discussed in the pages ahead. ${ }^{1}$ The first is a becquerel, which is a measure of the nuclear transformations in a radioisotope; one becquerel is equal to one radioactive disintegration per second. The unit is used to represent the amount of radioactivity in a sample, and I most often encountered it expressed in terms of weight, as in the number of becquerels present per kilogram. The food safety standards created by the Japanese government are expressed in becquerels per kilogram (bq/kg).

The second is the sievert (Sv), which measures the potential of ionizing radiation to cause harm and accounts for the type of radiation and the sensitivity of the tissues exposed. Doses are sometimes expressed temporally to represent a rate of exposure per hour or per year. The average exposure for the world population from natural sources is 2.4 millisieverts per year (mSv/year).

Exposure to low-level ionizing radiation affects the body by causing cells to die or mutate, which can increase the likelihood of developing cancer years or decades later. Studies have established that exposure to amounts in excess of $100 \mathrm{mSv}$ can lead to an increased incidence of cancer, but it is murky territory below those numbers (Brenner et al. 2003; Normile 2011). Scientific opinion is divided between researchers who believe there is no safe exposure level and others who believe that small amounts are unlikely to present significant health challenges. In her ethnography of Chernobyl, Petryna found a similar dynamic in which scientists told her that low exposure to radiation remains a "black box" (Petryna 2002, 17). Unfortunately, there is a lack of conclusive data on the effects of longterm low-level exposure to radiation. The hope is that the epidemiological studies currently underway in Fukushima will bring further clarity to this debate. ${ }^{2}$

\section{FOOD SAFETY STANDARDS}

On March 17, 2011, the Japanese government issued emergency standards to monitor radiation in the food supply. The standards were derived from the International Commission on Radiological Protection guidelines, which state that the general population should not be exposed to more than $5 \mathrm{mSv} /$ year. On this basis the Japanese government created standards for the radioactive substances emitted from the nuclear meltdown. 
Table 1. Changes in the regulation values for radioactive cesium

\begin{tabular}{|c|c|c|c|}
\hline \multicolumn{2}{|c|}{$\begin{array}{l}\text { Provisional regulation values for } \\
\text { radioactive cesium (March 2011) }\end{array}$} & \multicolumn{2}{|c|}{$\begin{array}{l}\text { New standard limits for radioactive } \\
\text { cesium (effective April 2012) }\end{array}$} \\
\hline Category & Limit $(b q / k g)$ & Category & Limit $(b q / k g)$ \\
\hline Drinking water & 200 & Drinking water & 10 \\
\hline Milk, dairy products & 200 & Milk & 50 \\
\hline Vegetables & & General foods & 100 \\
\hline Grains & 500 & Infant foods & 50 \\
\hline Meat, eggs, fish, etc. & & & \\
\hline
\end{tabular}

Source: Compiled from "Food and Radiation Q\&A," Consumer Affairs Agency, Government of Japan, 8th edition, May 2013, http://www.caa.go.jp/jisin/pdf/130902 _food_qa_en.pdf.

Note: The left table indicates the temporary values adopted in March 2011, and the right table shows the revised values.

The maximum allowable standard became $500 \mathrm{bq} / \mathrm{kg}$ for cesium and 2000 bq/kg for iodine (Berends and Kobayashi 2012; Hamada and Ogino 2012; Michino 2012). The standards for cesium were revised in April 2012 to a maximum of $100 \mathrm{bq} / \mathrm{kg}$ for general food products, while the iodine had decayed and was no longer a concern (Yamaguchi 2012). 
